\title{
Tegaserod in the treatment of irritable bowel syndrome (IBS) with constipation as the prime symptom
}

\author{
Peter Layer ${ }^{\prime}$ \\ Jutta Keller' \\ Helena Loeffler ${ }^{2}$ \\ Andreas Kreiss ${ }^{2}$ \\ 'Department of Internal Medicine, \\ Israelitisches Krankenhaus, Hamburg, \\ Germany; ${ }^{2}$ Clinical Development, \\ Novartis Pharma GmbH, Nuremberg, \\ Germany
}

\begin{abstract}
Irritable bowel syndrome with constipation (IBS-C) as the predominant bowel symptom is a prevalent disorder, characterized by recurring abdominal pain/discomfort, bloating, and constipation, and imposes a significant socio-economic burden. Traditional treatments generally address just one of the multiple IBS symptoms. The efficacy and safety profile of tegaserod, a serotonin $5-\mathrm{HT}_{4}$ receptor agonist, has been demonstrated in several randomized, placebo-controlled, and open-label trials. This review discusses the major clinical trials of tegaserod, which have involved 8948 IBS patients. Overall, data reveal that tegaserod is an effective treatment for IBS-C, providing statistically significant relief of overall and multiple individual IBS-C symptoms (abdominal pain/discomfort, bloating, and constipation) in both placebo-controlled and "real-life" open-label settings. Repeat treatments with tegaserod were also shown to be effective, which is noteworthy given the chronic and episodic nature of IBS. Moreover, tegaserod was associated with improvements in patients' quality of life and work productivity. Data also indicate that tegaserod is well tolerated over the short-term (4 weeks), long-term (12 months), and repeated treatments. Diarrhea is the only adverse event consistently associated with tegaserod and was generally mild and transient. Overall, tegaserod has been demonstrated to offer effective and well-tolerated treatment of IBS-C, providing patients with meaningful symptom relief.
\end{abstract}

Keywords: efficacy, IBS, safety, serotonin, tegaserod, Zelnorm

\section{Introduction}

\section{Prevalence and impact of IBS}

Irritable bowel syndrome (IBS) is a chronic and episodic gastrointestinal (GI) disorder. Cardinal symptoms include abdominal pain/discomfort, bloating, and altered bowel function, with the predominant bowel symptom determining the subclassification of IBS: IBS with constipation (IBS-C), IBS with diarrhea (IBS-D), or IBS with alternating symptoms of constipation or diarrhea (IBS-A). To date, no structural or specific biochemical markers have been identified for IBS and, therefore, its diagnosis is based on the recognition of key symptoms and exclusion of organic disease (Malagelada 2006). Several diagnostic guidelines have been established for IBS, including the Rome II criteria (Thompson et al 1999). Rome II criteria classify IBS as abdominal pain/discomfort associated with two out of three of the following features: relief with defecation, onset associated with a change in stool frequency ( $<3$ bowel movements per week or $>3$ bowel movements per day) and/or onset associated with a change in stool form (lumpy/hard or loose/watery stool), occurring for at least 12 weeks (not necessarily consecutive) in the preceding 12 months (Thompson et al 1999).

IBS is a common disorder, thought to affect approximately $10 \%-15 \%$ of individuals in Western countries (Hungin et al 2003, 2005). In addition, IBS is 
detrimental to patients' quality of life (QoL), affecting their daily routines, social lives, and emotional well-being (Hahn et al 1999; Gralnek et al 2000; Frank et al 2002). IBS also has a major economic impact on society due to its prevalence and the chronic and recurring nature of the symptoms. Studies have demonstrated that the total direct costs of IBS are similar to those of Alzheimer's disease, asthma, and migraine (Kozma et al 2002; Müller-Lissner and Pirk 2002). Given the prevalence and substantial socioeconomic impact of IBS, it is essential that effective and well-tolerated treatments are available.

\section{Current treatment options for IBS} Traditional pharmacological treatments

To date, there is no cure for IBS and so treatments are based on alleviating one or more of the multiple symptoms. A number of traditional pharmacological treatments are commonly used, including laxatives, antidiarrheal agents, antispasmodics, and low-dose antidepressants. Overall, these agents may be considered as suboptimal treatments for IBS since they each focus on just one symptom of this disorder (ie, constipation, diarrhea, or abdominal pain/ discomfort), leaving other symptoms untreated. For example, the antidiarrheal agent, loperamide, has been demonstrated to be effective for diarrhea, but does not reduce other or overall symptoms of IBS (Brandt et al 2002; Lesbros-Pantoflickova et al 2004). Consequently, patients may have to take several different medications to address their multiple symptoms. Furthermore, although these agents are often used as first-line treatments for IBS, evidence for their efficacy is limited. This is due, in part, to a lack of randomized, controlled clinical trials or inadequate trial design, as highlighted by several reviews of clinical trials for IBS treatments (Brandt et al 2002; Lesbros-Pantoflickova et al 2004; Valenzuela et al 2004; Quartero et al 2005).

Along with efficacy, safety and tolerability are important issues for IBS pharmacologic therapies, as patients are likely to require long-term and repeated treatment. However, conventional IBS therapies can cause side effects that mimic or exacerbate other IBS symptoms. For example, bulking laxatives may increase bloating and abdominal pain/ discomfort in some IBS patients, while some tricyclic antidepressants and antispasmodics may cause constipation (Brandt et al 2002).

\section{Serotonergic agents}

In addition to traditional pharmacotherapies, serotonergic agents are also used to treat IBS symptoms. Serotonin is a key neurotransmitter in the GI tract, where it is released in response to changes in luminal pressure or content of the small intestine. Serotonin stimulates the release of other neurotransmitters and together these influence intestinal peristalsis, secretion of water, and visceral sensation (Gershon 1999, 2004; Crowell 2004). Recent findings suggest that patients with IBS have abnormalities in the synthesis and function of serotonin in the GI tract (Coates et al 2004; Camilleri 2005). This is thought to lead to the key symptoms of IBS, such as abdominal pain/discomfort and altered bowel motility.

Alosetron and cilansetron are serotonergic agents with serotonin type $3\left(5-\mathrm{HT}_{3}\right)$ receptor antagonist actions, while cisapride has a mixed $5-\mathrm{HT}_{3}$ antagonist $/ 5-\mathrm{HT}_{4}$ receptor agonist action. Alosetron has been shown to relieve global and individual symptoms of IBS-D (Brandt et al 2002; Lesbros-Pantoflickova et al 2004; Valenzuela et al 2004; Quartero et al 2005), but has been associated with severe constipation and ischemic colitis and, since June 2002, the US Food and Drug Administration (FDA) restricted its license to women with severe IBS-D who fail to respond to other therapies. Cilansetron is currently in clinical development as a treatment for IBS-D, although it may also be associated with an increased incidence of ischemic colitis. Regulatory bodies have requested further clinical trials be conducted before they will consider licensing this treatment. Some, but not all, studies demonstrate that cisapride improves individual symptoms of IBS-C, including constipation and abdominal pain/discomfort. However, following reports of serious cardiac side effects unrelated to the $5-\mathrm{HT}_{3}$ antagonist $/ 5 \mathrm{HT}_{4}$ receptor agonist actions, cisapride is only available to patients who meet strict inclusion criteria in limited countries (Ferriman 2000; Wang et al 2001; Barbey et al 2002).

Tegaserod $\quad\left(Z\right.$ elnorm ${ }^{\circledR} /$ Zelmac $^{\circledR}, \quad$ Novartis Pharmaceuticals Inc) has a different mode of action to alosetron and cisapride. It acts as a serotonin 5- $\mathrm{HT}_{4}$ receptor agonist, and is without $5-\mathrm{HT}_{3}$ antagonistic properties or affinity for dopamine receptors (Pfannkuche et al 1995). Tegaserod is structurally similar to serotonin except it is more polar, which minimizes its potential to cross the bloodbrain barrier. Preclinical and clinical studies reveal that tegaserod can facilitate GI motility and intestinal secretion and reduce visceral sensitivity, thereby increasing the frequency of bowel movements, softening stools, and reducing abdominal pain/discomfort (Fioramonti et al 1998; Grider et al 1998; Jin et al 1999; Schikowski et al 1999; Stoner et al 1999; Prather et al 2000; Degen et al 2001; 
Coffin et al 2003; Sabate et al 2005). Recent reviews of clinical trial data suggest that tegaserod effectively relieves individual and global symptoms of IBS-C and has a favorable safety profile (Brandt et al 2002; LesbrosPantoflickova et al 2004; Valenzuela et al 2004; Schoenfeld 2005).

The aim of this paper is to review tegaserod as a treatment for IBS-C with particular focus on clinical trial data. The trials discussed in depth are divided into the four pivotal phase III trials involving 5859 IBS patients, three of which were the basis of FDA approval of tegaserod as a treatment for IBS-C, and six additional phase IIIb/IV trials involving 3089 IBS patients, which include open-label, repeat treatment studies to reflect "real-life" clinical practice. Data on the safety and tolerability of tegaserod following shortand long-term treatment are also discussed, along with special safety considerations.

\section{Pivotal phase III clinical trials of tegaserod \\ Trial designs}

The tegaserod clinical trial program includes four pivotal trials, which were conducted throughout 26 countries (Lefkowitz et al 1999; Müller-Lissner et al 2001; Novick et al 2002; Tack et al 2005). They employed randomized, multicenter, double-blind, placebo-controlled designs and each involved large numbers of IBS-C patients (Table 1).

All the pivotal trials incorporated a treatment-free baseline period, during which IBS-C symptoms were assessed. This was followed by a 12 -week treatment period in Studies 1-3 (Lefkowitz et al 1999; Müller-Lissner et al 2001; Novick et al 2002) and a withdrawal period in Study 3 only (Novick et al 2002). The primary efficacy variable for Studies 1-3 was Subject's Global Assessment (SGA) of Relief (Lefkowitz et al 1999; Müller-Lissner et al 2001;

Table I Overview of the design of the pivotal trials of tegaserod in IBS-C patients

\begin{tabular}{|c|c|c|c|c|}
\hline & $\begin{array}{l}\text { Study I } \\
\text { (Müller-Lissner et al } \\
200 I \text { ) }\end{array}$ & $\begin{array}{l}\text { Study } 2 \\
\text { (Lefkowitz et al 1999) }\end{array}$ & $\begin{array}{l}\text { Study } 3 \\
\text { (Novick et al 2002) }\end{array}$ & $\begin{array}{l}\text { ZENSAA } \\
\text { (Tack et al 2005) }\end{array}$ \\
\hline Location & Europe, South Africa, USA & $\begin{array}{l}\text { North and South America } \\
\text { America, South Africa }\end{array}$ & USA Europe, North and & uth \\
\hline Design & $\begin{array}{l}\text { - 4-week baseline }{ }^{\mathrm{a}} \\
\text { - } 12 \text {-week treatment }\end{array}$ & $\begin{array}{l}\text { - 4-week baseline }{ }^{\mathrm{a}} \\
\text { - } \quad \text { 12-week treatment }\end{array}$ & $\begin{array}{l}\text { - 4-week baseline }{ }^{\mathrm{a}} \\
\text { - } 12 \text {-week treatment } \\
\text { - } 4 \text {-week withdrawal }\end{array}$ & $\begin{array}{l}\text { - } 2 \text {-week baseline }{ }^{\mathrm{a}} \\
\text { Two 4-week treatment } \\
\text { periods separated by } \\
\text { treatment-free interval }\end{array}$ \\
\hline Treatment $^{b}$ & $\begin{array}{l}\text { Tegaserod } 6 \mathrm{mg} \text { bid } \\
\text { Tegaserod } 2 \mathrm{mg} \text { bid } \\
\text { Placebo }\end{array}$ & $\begin{array}{l}\text { Tegaserod } 6 \mathrm{mg} \text { bid } \\
\text { Tegaserod } 2 \mathrm{mg} \text { bid } \\
\text { Placebo }\end{array}$ & $\begin{array}{l}\text { Tegaserod } 6 \mathrm{mg} \text { bid } \\
\text { Placebo }\end{array}$ & $\begin{array}{l}\text { Tegaserod } 6 \mathrm{mg} \text { bid } \\
\text { Placebo }\end{array}$ \\
\hline Patients $^{c}$ & 881 men and women & 799 men and women & 1519 women only & 2660 women only \\
\hline Primary outcome variable ${ }^{d}$ & SGA of Relief & SGA of Relief & SGA of Relief & $\begin{array}{l}\text { - Satisfactory relief of } \\
\text { overall IBS symptoms } \\
\text { - Satisfactory relief of } \\
\text { abdominal discomfort/pain }\end{array}$ \\
\hline $\begin{array}{l}\text { Secondary outcome } \\
\text { variables }\end{array}$ & $\begin{array}{l}\text { - SGA of Abdominal } \\
\text { Pain/Discomfort } \\
\text { - Effect on: } \\
\text { - Abdominal } \\
\text { discomfort/pain } \\
\text { - Bloating } \\
\text { - Stool frequency } \\
\text { - Stool consistency }\end{array}$ & $\begin{array}{l}\text { - SGA of Abdominal } \\
\text { Pain/Discomfort } \\
\text { - Effect on: } \\
\text { - Abdominal } \\
\text { discomfort/pain } \\
\text { - Bloating } \\
\text { - Stool frequency } \\
\text { - Stool consistency }\end{array}$ & $\begin{array}{l}\text { - SGA of Abdominal } \\
\text { Pain/Discomfort } \\
\text { - SGA of Bowel Habit } \\
\text { - SGA of Satisfaction } \\
\text { with Bowel Habit } \\
\text { - Effect on: } \\
\text { - Abdominal } \\
\text { - } \text { discomfort/pain } \\
\text { - Stoating } \\
\text { - Stool frequency } \\
\text { - Stool consistency }\end{array}$ & $\begin{array}{l}\text { Effect on: } \\
\text { - } \text { Abdominal } \\
\text { discomfort/pain } \\
\text { - Bloating } \\
\text { - } \text { Stool frequency } \\
\text { - } \text { Stool consistency } \\
\text { - Overall satisfaction } \\
\text { with treatment } \\
\text { - IBS-QOL,EQ-5D, } \\
\text { WPAI:IBS-C } \\
\text { questionnaires }\end{array}$ \\
\hline
\end{tabular}

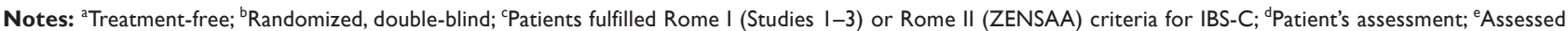
using ordinal scales. Patients had broadly similar demographic characteristics and baseline symptoms between the four studies.

Abbreviations: bid, twice daily; EQ-5D, EuroQoL; IBS, irritable bowel syndrome; IBS-QOL, IBS-specific quality of life; WPAI: IBS-C, Work productivity activity impairment for IBS with constipation; SGA, Subject's Global Assessment, measured by a patient's response to the question "Please consider how you felt this last week in regard to your IBS, in particular your overall well-being and symptoms of abdominal pain/discomfort and altered bowel habit." Compared with baseline, patients rated their symptoms on a 5-point scale: completely relieved, considerably relieved, somewhat relieved, unchanged, or worse. 
Novick et al 2002). This is an important outcome variable due to the varying importance that patients place on their different IBS symptoms (Dunger-Baldauf et al 2003). Responders were patients whose symptoms were "completely relieved" or "considerably relieved" at least $50 \%$ of the time or "somewhat relieved" $100 \%$ of the time during the final 4 weeks of the study. Patients also assessed their individual IBS symptoms as secondary efficacy variables (Table 1).

IBS patients often require repeat courses of therapy due to the chronic and episodic nature of their symptoms and, as recommended by the European Committee for Medicinal Products for Human Use (CHMP; formally known as the Committee for Proprietary Medicinal Products [CPMP]), it is important that treatment can be repeated without loss of efficacy (CPMP 2003). Therefore, Study 4 (ZENSAA,

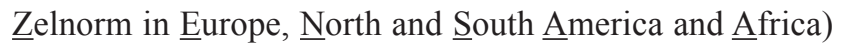
investigated the effects of repeat tegaserod treatment. Patients who responded to initial treatment (4 weeks) entered a treatment-free interval. Patients were randomized to receive a further 4 weeks of either tegaserod or placebo if their symptoms recurred during this interval. The ZENSAA trial utilized two primary efficacy variables: whether patients experienced satisfactory relief of their overall IBS symptoms, and whether patients experienced satisfactory relief of their abdominal discomfort/pain during the last week (yes/no). Responders were patients with satisfactory relief during at least 3 weeks of each 4-week treatment cycle (Tack et al 2005). Effects of treatment on individual IBS symptoms were also assessed, along with patients' QoL and work productivity, examined via IBS-QOL (IBS-specific QoL), EQ-5D (EuroQoL) and WPAI:IBS-C (Work Productivity Activity Impairment for IBS-C) questionnaires, along with their overall satisfaction with treatment (Table $1)$.

\section{Efficacy data}

Data from all four trials reveal that tegaserod was consistently and significantly better than placebo at relieving overall and key individual IBS symptoms (Lefkowitz et al 1999; Müller-Lissner et al 2001; Novick et al 2002; Tack et al 2005). The main findings from each of the pivotal trials are summarized in Table 2.

In Studies 1-3, tegaserod provided significantly greater relief of overall IBS symptoms during nearly all weeks of treatment compared with placebo $(\mathrm{p}<0.05$, Figure 1) (Lefkowitz et al 1999; Müller-Lissner et al 2001; Novick et al 2002). Tegaserod also significantly improved individual IBS symptoms, including abdominal pain/discomfort, bloating, and constipation (increased stool frequency and

Table 2 Overview efficacy findings of the pivotal trials of tegaserod in IBS-C patients

\begin{tabular}{|c|c|c|}
\hline & Primary efficacy variables $^{a}$ & Secondary efficacy variables \\
\hline $\begin{array}{l}\text { Study I } \\
\text { (Müller-Lissner et al 200I) }\end{array}$ & $\begin{array}{l}\text { - Greater SGA of relief of overall IBS } \\
\text { symptoms for II out of I } 2 \text { weeks } \\
\text { (tegaserod vs placebo, } \mathrm{p} \leq 0.05 \text { ) } \\
\text { - At endpoint, treatment difference } \\
\text { from placebo was } 11.8 \% \text { and } 12.7 \% \\
\text { for } 2 \mathrm{mg} \text { and } 6 \mathrm{mg} \text { tegaserod, } \\
\text { respectively }\end{array}$ & $\begin{array}{l}\text { Greater improvements in abdominal } \\
\text { pain/discomfort, stool frequency, stool consistency } \\
\text { during most weeks (tegaserod vs placebo, } \mathrm{p}<0.05 \text { ) } \\
\text { - Favorable trend for tegaserod reducing the number } \\
\text { of days with bloating }\end{array}$ \\
\hline $\begin{array}{l}\text { Study } 2 \\
\text { (Lefkowitz et al 1999) }\end{array}$ & $\begin{array}{l}\text { - Greater SGA of overall relief at } \\
\text { Months I and } 2 \text { (tegaserod vs placebo, } \\
\mathrm{P}<0.05 \text { ), but not at study endpoint }\end{array}$ & $\begin{array}{l}\text { - Improved abdominal pain/discomfort, bloating, stool } \\
\text { frequency, and stool consistency (tegaserod vs } \\
\text { placebo, } p<0.05 \text { ) }\end{array}$ \\
\hline $\begin{array}{l}\text { Study } 3 \\
\text { (Novick et al 2002) }\end{array}$ & $\begin{array}{l}\text { - Greater SGA of relief of overall IBS } \\
\text { symptoms for II out of } 12 \text { weeks } \\
\text { (tegaserod vs placebo, } \mathrm{p} \leq 0.05 \text { ) } \\
\text { - At endpoint, treatment difference } \\
\text { between tegaserod and placebo was } 4.7 \%\end{array}$ & $\begin{array}{l}\text { - Improved SGAs of abdominal pain/discomfort, bowel } \\
\text { habit and satisfaction with bowel habit, and } \\
\text { symptoms of bloating, stool frequency, stool } \\
\text { consistency and days with straining (tegaserod vs } \\
\text { placebo, } \mathrm{p}<0.05 \text { ) }\end{array}$ \\
\hline $\begin{array}{l}\text { ZENSAA } \\
\text { (Tack et al 2005) }\end{array}$ & $\begin{array}{l}\text { More tegaserod than placebo responders } \\
\text { during initial and repeat treatment for } \\
\text { satisfactory relief of overall IBS symptoms: } \\
33.7 \% \text { vs } 24.2 \%, 44.9 \% \text { vs } 28.7 \% \text {; and relief } \\
\text { of abdominal discomfort/pain: } 31.3 \% \\
\text { vs } 22.1 \%, 42.4 \% \text { vs } 27.1 \% \text {; all } p<0.000 \text { I) }\end{array}$ & $\begin{array}{l}\text { Greater relief during initial and repeated treatment } \\
\text { from abdominal discomfort/pain, bloating, and } \\
\text { improvements in stool frequency and stool } \\
\text { consistency (tegaserod vs placebo, } \mathrm{p} \leq 0.00 \mathrm{I} \text { ) } \\
\text { Greater treatment satisfaction, work productivity } \\
\text { and improvements in QoL (tegaserod vs placebo, } \\
\mathrm{P}<0.05 \text { ) }\end{array}$ \\
\hline
\end{tabular}

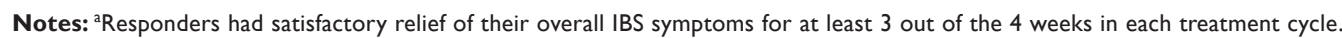

Abbreviations: IBS-C, irritable bowel syndrome with constipation; SGA, Subject's Global Assessment; QoL, quality of life. 
softened stools) compared with placebo (Lefkowitz et al 1999; Müller-Lissner et al 2001; Novick et al 2002). After withdrawal of treatment, IBS symptoms returned rapidly, but did not reach baseline levels (Novick et al 2002).

In the ZENSAA trial, tegaserod treatment was associated with significantly more responders for relief of overall IBS symptoms (Figure 1) and relief of abdominal discomfort/ pain compared with placebo $(\mathrm{p}<0.0001)$. This occurred during both initial and repeat treatments (Tack et al 2005). Similar to the other pivotal studies, tegaserod was also superior to placebo for relief of individual IBS symptoms, including bloating and constipation, following initial and repeat treatments $(p \leq 0.001)$. Furthermore, during both treatment cycles, more patients expressed overall satisfaction with tegaserod compared with placebo $(56.2 \%$ vs $41.2 \%$; $66.1 \%$ vs $50.1 \%$, both $\mathrm{p}<0.0001$ ) (Tack et al 2005 ). Similar to Study 3, IBS symptoms recurred gradually following cessation of treatment, with no evidence of a rebound effect (Tack et al 2005). Overall, these findings suggest that many patients who benefit from an initial course of tegaserod treatment are likely to benefit from a further course, should their symptoms recur (Tack et al 2005). It is noteworthy that no other IBS treatments have been shown to effectively address bloating, which is one of the symptoms IBS patients report as most bothersome (Schmulson et al 1999; Bijkerk et al 2003).

In the ZENSAA trial, the positive effect of tegaserod on IBS symptom relief was mirrored by significant improvements in QoL and health economic-related outcomes. In tegaserod-treated patients, IBS-QOL scores were significantly higher in five out of the eight domains (dysphoria, body image, health worry, food avoidance, and impact on relationships; $\mathrm{p}<0.05$ ) compared with placebo (Patrick et al 2005; Tack et al 2005). Less presenteeism (impairment while at work), absenteeism (work time missed), and overall work productivity loss were also observed in tegaserod than placebo patients $(\mathrm{p}<0.0001)$, equating to an increase of 2.5 hours' work productivity per week (Reilly et al 2005; Tack et al 2005).

In all four pivotal trials, response to tegaserod was rapid and sustained. For each of the variables, response occurred within the first week of treatment (illustrated for stool frequency in Figure 2) and continued throughout the treatment period (illustrated for abdominal pain/discomfort in Figure 3), with no evidence of tachyphylaxis (Lefkowitz et al 1999; Müller-Lissner et al 2001; Novick et al 2002; Tack et al 2005). Moreover, the response rate for tegaserod tended to increase during the course of treatment (Figure

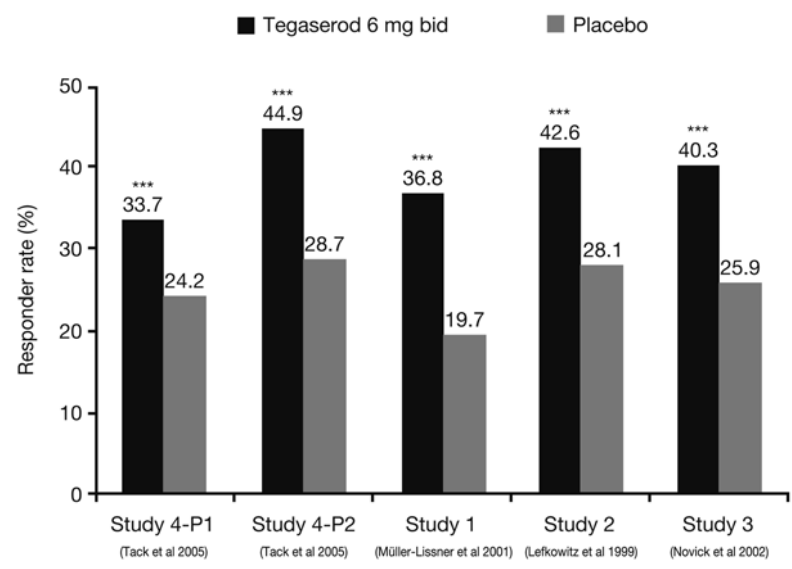

Figure I Subject's Global Assessment (SGA) of Relief demonstrates consistent improvement across tegaserod clinical trials. Note: $* * * p<0.001$.

Abbreviations: $\mathrm{PI}$, first treatment cycle; $\mathrm{P} 2$, second treatment cycle.

4). These data indicate that patients who do not respond to tegaserod during the first few weeks of treatment may go on to respond a few weeks later if treatment is continued.

The placebo effect (a response to a pharmacologically inactive therapy) is well documented in trials of patients with functional bowel diseases (Patel et al 2005). Estimates of response to placebo in IBS trials are typically between $40 \%$ and $70 \%$, making it difficult to detect a therapeutic gain with active treatment (Patel et al 2005). However, it is noteworthy that in each of the four key tegaserod IBS trials, a statistically significant greater response to treatment was observed for tegaserod compared with placebo. For overall symptom relief, response above placebo for tegaserod ranged between $4.7 \%$ and $16.2 \%$ (Lefkowitz et al 1999; Müller-Lissner et al 2001; Novick et al 2002; Tack et al 2005). Numbers needed to treat (NNT) to derive benefit

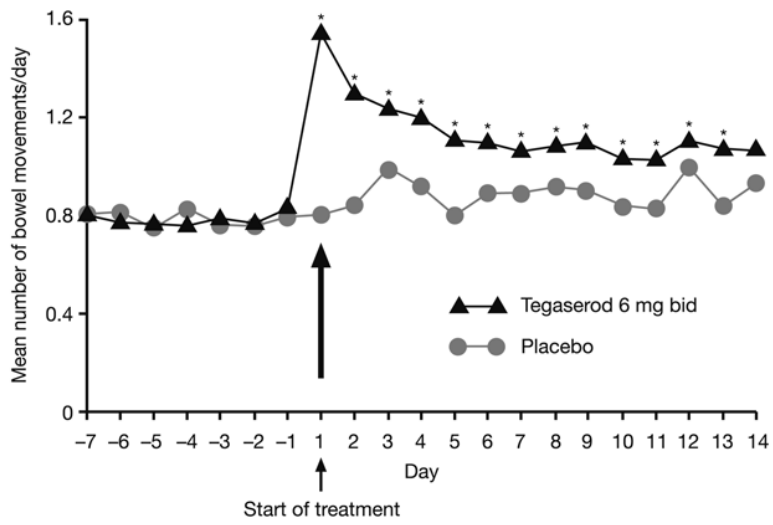

Figure 2 Rapid onset of action with tegaserod: increased number of bowel movements. Pooled data from Studies I and 2 (Leftkowitz et al 1999; MüllerLissner et al 200I; Novartis. Data on file).

Note: ${ }^{*} p<0.05$ vs placebo (change from baseline score). 


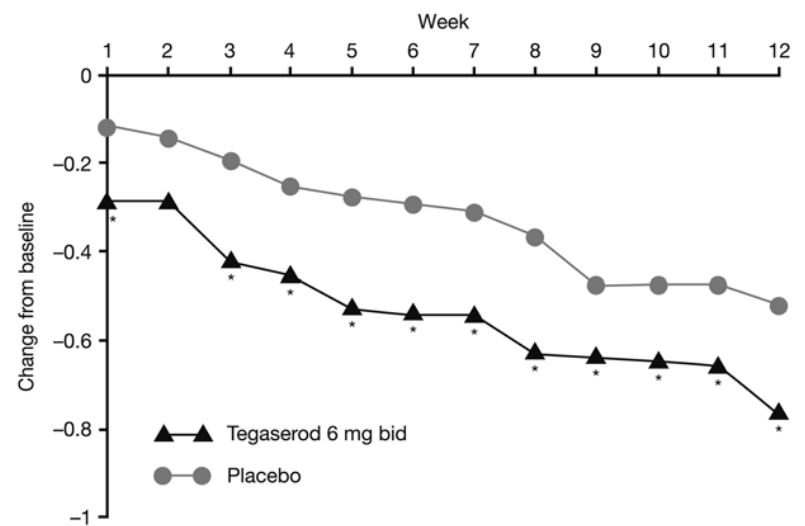

Figure 3 Sustained effect of tegaserod: improved abdominal pain and discomfort. Study I. Copyright (C) 200I. Figure adapted with permission from the Blackwell Publishing Group from Müller-Lissner SA, Fumagalli I, Bardhan KD, et al. 200 I. Tegaserod, a $5-\mathrm{HT}_{4}$ receptor partial agonist, relieves symptoms in irritable bowel syndrome patients with abdominal pain, bloating and constipation. Aliment PharmacolTher, 15:1655-66.

Note: 6 -point scale: $0=$ absent to $5=$ very severe; ${ }^{*} p<0.05$ vs placebo (change from baseline score).

calculated for women aged $\leq 65$ years in the pivotal trials were 5.6, 6.8, and 7.0 for Studies 1, 2, and 3, respectively, based on the definition of responder (patients whose symptoms were "completely relieved" or "considerably relieved" at least $50 \%$ of the time or "somewhat relieved" $100 \%$ of the time during the final four weeks of the study). NNT for Study 4 was 10.8 and 6.0 for initial and repeated treatment respectively, based on the definition of responder (patients with satisfactory relief during at least 3 weeks of each 4-week treatment cycle) (Novartis. Data on file).

\section{Further phase IIIb/IV clinical trials of tegaserod in IBS-C}

The aim of these six phase IIIb/IV studies was to further assess tegaserod treatment in IBS patients of differing race and culture from a wide range of countries (Kellow et al 2003; Uscanga-Dominguez and Cohen Munoz 2003; Bardhan et al 2004; Nyhlin et al 2004; Layer et al 2005; Müller-Lissner et al 2005). While two of these trials followed similar randomized, placebo-controlled designs to the pivotal IBS trials, the others were open-labeled and designed to evaluate the effectiveness of tegaserod under real-life conditions (Table 3).

Data from the two randomized, placebo-controlled trials (Kellow et al 2003; Nyhlin et al 2004) were consistent with the four pivotal trials (Lefkowitz et al 1999; Müller-Lissner et al 2001; Novick et al 2002; Tack et al 2005). They demonstrated that significantly more patients taking tegaserod than placebo experienced satisfactory relief of their overall IBS symptoms and greater improvements in individual symptoms, including abdominal pain/discomfort, stool frequency, stool consistency, and straining during defecation. These results confirm that tegaserod is an effective treatment for overall and individual symptoms of IBS, irrespective of factors such as geographical region, race, and culture. In addition, as two of these trials were conducted in IBS patients excluding those with diarrhea (non-IBS-D), they also indicate that tegaserod is effective in this subgroup of patients, as well as those diagnosed with IBS-C according to Rome II criteria.

Three of the phase IIIb/IV studies investigated the effects of repeated tegaserod treatment (Uscanga-Dominguez and Cohen Munoz 2003; Bardhan et al 2004; Müller-Lissner et al 2005). These were open-label studies and are more likely to reflect clinical practice than placebo-controlled trials. In the UK and Latin American retreatment studies, patients who responded to initial tegaserod therapy (satisfactory relief of overall IBS symptoms for at least 2 out of 4 weeks' treatment) were randomized to either continue on tegaserod or withdraw from treatment. In both studies, almost $60 \%$ more patients who withdrew from tegaserod experienced symptom recurrence compared with those who continued therapy $(\mathrm{p}<0.0001)$ (Uscanga-Dominguez and Cohen Munoz 2003; Bardhan et al 2004) (Table 3). A significant treatment benefit for abdominal pain/discomfort, bloating (both $\mathrm{p} \leq 0.02$ ) (Uscanga-Dominguez and Cohen Munoz 2003; Bardhan et al 2004), stool frequency, and overall symptom relief (both $\mathrm{p}<0.0004$ ) was observed in patients who continued tegaserod treatment compared with those who withdrew (Uscanga-Dominguez and Cohen Munoz

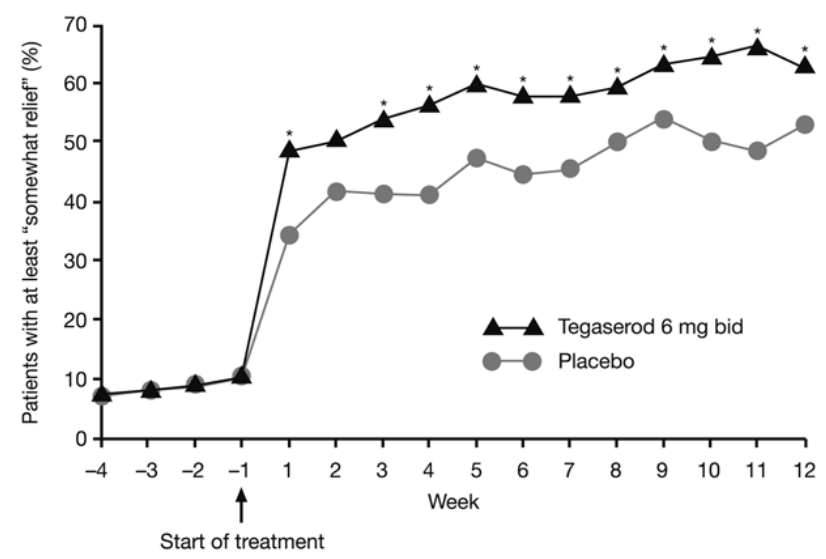

Figure 4 Subject's Global Assessment (SGA) of Relief during tegaserod treatment. Study I. Copyright (C) 200I. Figure reproduced with permission from the Blackwell Publishing Group from Müller-Lissner SA, Fumagalli I, Bardhan KD, et al. 200 I. Tegaserod, a 5- $\mathrm{HT}_{4}$ receptor partial agonist, relieves symptoms in irritable bowel syndrome patients with abdominal pain, bloating and constipation. Aliment Pharmacol Ther, 15:1655-66.

Note: ${ }^{*} \mathrm{p}<0.05$ vs placebo. 
Table 3 Overview of the design and key efficacy outcomes of the additional Phase IIIb/IV trials of tegaserod in IBS patients

\begin{tabular}{|c|c|c|c|}
\hline & \multicolumn{3}{|l|}{ Study characteristics } \\
\hline & Patients $^{\mathrm{a}}$ & Study design & Key findings \\
\hline $\begin{array}{l}\text { ZAP } \\
\text { (Kellow et al 2003) }\end{array}$ & $\begin{array}{l}\mathrm{n}=520 \text { (non-IBS-D) } \\
\text { Asia-Pacific countries }\end{array}$ & $\begin{array}{l}\text { RCT } \\
\text { - } 2 \text {-week baseline } \\
\text { - } 12 \text { weeks' treatment } \\
\text { (tegaserod } 6 \mathrm{mg} \text { bid or } \\
\text { placebo) } \\
\text { - } 4 \text {-week withdrawal }\end{array}$ & $\begin{array}{l}\text { More tegaserod than placebo responders }{ }^{\mathrm{b}} \text { over } \\
\text { Weeks } \mathrm{I}-4(56 \% \text { vs } 35 \%) \text { and Weeks } \mathrm{I}-12(62 \% \text { vs } \\
44 \% ; \mathrm{p}<0.000 \mathrm{I}) \\
\text { Greater reductions in days without bowel } \\
\text { movements, hard/very hard stools, straining, } \\
\text { sensation of incomplete evacuation for tegaserod vs } \\
\text { placebo }(\mathrm{p}<0.05) \text {, but not for abdominal pain }\end{array}$ \\
\hline $\begin{array}{l}\text { TENOR } \\
\text { (Nyhlin et al 2004) }\end{array}$ & $\begin{array}{l}\mathrm{n}=647 \text { (non-IBS-D) } \\
\text { Nordic countries }\end{array}$ & $\begin{array}{l}\text { RCT } \\
\text { - } 2 \text {-week baseline } \\
\text { - } 12 \text { weeks' treatment } \\
\text { (tegaserod } 6 \mathrm{mg} \text { bid or } \\
\text { placebo) } \\
\text { - } 4 \text {-week withdrawal }\end{array}$ & $\begin{array}{l}\text { More tegaserod than placebo responders }{ }^{\mathrm{b}}(54 \% \text { and } \\
78 \% \text { higher for Weeks } \mathrm{I}-4 \text { and Weeks } \mathrm{I}-\mathrm{I} \text {, } \\
\text { respectively; } \mathrm{p}<0.005) \\
\text { Greater reductions in days without bowel } \\
\text { movements, hard/very hard stools, straining, } \\
\text { sensation of incomplete evacuation for tegaserod vs } \\
\text { placebo patients ( } \mathrm{p}<0.05) \text {, but not for abdominal } \\
\text { pain/discomfort and bloating }\end{array}$ \\
\hline $\begin{array}{l}\text { German retreatment } \\
\text { (Müller-Lissner et al 2005) }\end{array}$ & $\begin{array}{l}\mathrm{n}=513\left(\mathrm{IBS}-\mathrm{C}^{\mathrm{c}}\right) \\
\text { Germany }\end{array}$ & $\begin{array}{l}\text { Open-label } \\
\text { - } 2 \text {-week baseline } \\
\text { - } 12 \text { weeks' treatment } \\
\text { (tegaserod } 6 \mathrm{mg} \text { bid) } \\
\text { - } 8 \text {-week withdrawal } \\
\text { - } 4 \text { weeks' treatment } \\
\text { (tegaserod } 6 \mathrm{mg} \text { bid) }\end{array}$ & $\begin{array}{l}\text { - } 85 \% \text { were responders } \mathrm{b}^{\mathrm{b}} \text { in first treatment cycle } \\
\text { Recurrence of symptoms in } 83.9 \% \text { after a mean of } \\
38 \text { days without treatment } \\
\text { - } 89.3 \% \text { were responders } \mathrm{s}^{\mathrm{b}} \text { during retreatment }\end{array}$ \\
\hline $\begin{array}{l}\text { UK retreatment } \\
\text { (Bardhan et al 2004) }\end{array}$ & $\begin{array}{l}\mathrm{n}=519\left(\mathrm{IBS}-\mathrm{C}^{\mathrm{C}}\right) \\
\text { UK }\end{array}$ & 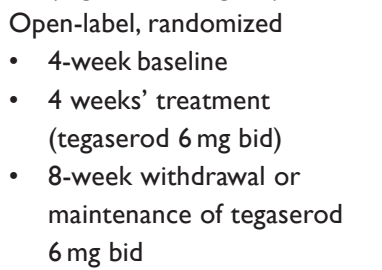 & $\begin{array}{l}\text { Shorter time to symptom recurrence in withdrawal } \\
\text { vs tegaserod patients. More tegaserod patients } \\
\text { without symptom recurrence by Week } 8 \text { vs patients } \\
\text { on intermittent }(86.5 \% \text { vs } 58.1 \%) \text { or withdrawal of } \\
\text { treatment }(69.2 \% \text { vs } 11.3 \%, p<0.000 \mathrm{I}) \\
\text { - Significant reductions for bloating }(\mathrm{p}<0.0 \mathrm{I}) \text { and } \\
\text { abdominal pain/discomfort }(\mathrm{p}<0.02)\end{array}$ \\
\hline $\begin{array}{l}\text { LATAM } \\
\text { (Uscanga-Dominguez } \\
\text { and Cohen Munoz } \\
\text { 2003) }\end{array}$ & $\begin{array}{l}\mathrm{n}=678(\text { IBS-C } \\
\text { Latin America }\end{array}$ & 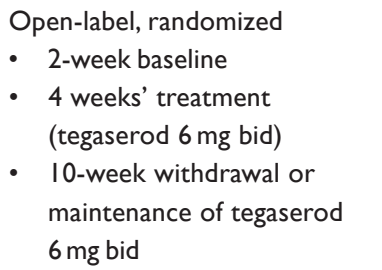 & $\begin{array}{l}\text { - } 82 \% \text { experienced overall symptom relief } \\
\text { on tegaserod vs those withdrawn ( } 10 \% \text { vs } 67 \% \text {, } \\
p<0.000 \text { I) }\end{array}$ \\
\hline $\begin{array}{l}\text { German primary care } \\
\text { (Layer et al 2005) }\end{array}$ & $\begin{array}{l}\mathrm{n}=2 \mathrm{I} 2(\mathrm{IBS}-\mathrm{C}) \\
\text { Germany }\end{array}$ & $\begin{array}{l}\text { Open-label } \\
\text { - } 2 \text {-week baseline } \\
\text { - } 12 \text { weeks' treatment } \\
\text { (tegaserod } 6 \mathrm{mg} \text { bid) } \\
\text { - 9-month optional treatment } \\
\text { extension (tegaserod } \\
6 \mathrm{mg} \text { bid) }\end{array}$ & $\begin{array}{l}\text { Response rates }{ }^{\mathrm{b}}: 64.2 \% \text { at Week } 4,70.3 \% \text { at } \\
\text { Week I2 } \\
\text { After I } 2 \text { weeks, significant reductions in abdominal } \\
\text { pain/discomfort and bloating ( }<<0.000 \mathrm{I}) \text { and } \\
\text { improvements in stool frequency and stool } \\
\text { consistency }(\mathrm{p}<0.000 \mathrm{I})\end{array}$ \\
\hline
\end{tabular}

Notes: ${ }^{\mathrm{a}}$ Men and women; ${ }^{\mathrm{b}}$ Responders had satisfactory relief of their overall IBS symptoms for at least 2 out of the 4 preceding weeks; ${ }^{\mathrm{C}}$ IBS-C classified according to Rome II criteria.

Abbreviations: bid, twice daily; IBS-D, irritable bowel syndrome with diarrhea; RCT, randomized, controlled trial; IBS-C, irritable bowel syndrome with constipation.

2003). In the German retreatment study, withdrawal of tegaserod resulted in symptom recurrence in the majority of patients $(83.9 \%)$, while retreatment of responders to initial therapy, following symptom recurrence, was effective in over $90 \%$ of patients. Similar improvements from baseline in symptoms of abdominal pain, bloating, stool frequency and consistency were also observed following both the initial $(p \leq 0.0003)$ and repeated treatments with tegaserod (MüllerLissner et al 2005).

A second open-label study conducted in Germany investigated the effectiveness of tegaserod in "real-life" primary care settings, focusing on patients with mild or moderate IBS (Layer et al 2005). Response rates for overall IBS symptom relief (satisfactory relief of IBS symptoms 
for 2 out of 4 of the previous weeks) increased during treatment and by Week 12, there were significant improvements in abdominal pain/discomfort, bloating, stool frequency, and consistency from baseline $(p<0.0001)$ (Layer et al 2005).

In summary, findings from these clinical trials demonstrate that tegaserod is an effective treatment for IBS. Tegaserod is associated with significant relief, compared with placebo or baseline, of overall and individual symptoms of IBS, in IBS-C and non-IBS-D patients from a wide range of countries throughout the world. Repeated use of tegaserod is effective, particularly in patients who previously responded to treatment.

\section{Safety and tolerability of tegaserod: data from IBS clinical trials}

Safety and tolerability were studied extensively throughout the tegaserod IBS clinical trial program. All reported adverse events (AEs) and serious adverse events (SAEs) were considered, alongside outcomes of physical examinations, standard hematology and biochemistry testing, urinalysis, blood pressure, and electrocardiogram (ECG) evaluations.

The available data demonstrate that tegaserod has a favorable safety profile and is well tolerated by IBS-C patients. Overall, the incidences of AEs and SAEs were comparable between patients who received tegaserod or placebo, with the exception of diarrhea, which was more frequent in patients taking tegaserod. A meta-analysis of three IBS-C trials of tegaserod revealed that diarrhea occurred in $10.0 \%$ and $4.2 \%$ of tegaserod and placebo patients, respectively, and was rated as severe in $3.1 \%$ and $0.9 \%$ of patients (Earnest et al 2002). Diarrhea is an anticipated $\mathrm{AE}$ associated with tegaserod use, given its promotile activity in the GI tract. In most cases diarrhea was experienced as a single episode, was mild and transient, and resolved without the need to interrupt the study drug or provide therapeutic intervention (Hasler and Schoenfeld 2004). The incidence of serious consequences of diarrhea, such as hypovolemia, hypotension, and syncope, was very rare, occurring in 3 out of 9267 patients $(0.03 \%)$ who participated in phase II and III trials of tegaserod across all indications (Novartis. Data on file).

Along with diarrhea, headache was also one of the most frequently reported AEs in these trials. The effect of tegaserod on headache is inconclusive since the incidence was similar in tegaserod and placebo-assigned patients in some studies (30.6\% vs 27.3\% [Müller-Lissner et al 2001] and $12.0 \%$ vs $11.1 \%$ [Kellow et al 2003] for tegaserod and placebo patients, respectively) but was more frequent with tegaserod in others (9.0\% vs 5.7\% [Novick et al 2002] and $8.0 \%$ vs $4.7 \%$ [Nyhlin et al 2004]). Other safety data from these trials indicated that no clinically relevant abnormalities in hematology, biochemistry, or ECG parameters were associated with tegaserod treatment.

Figure 5 shows a pooled analysis of AEs leading to discontinuation from the three pivotal IBS-C trials of 12 weeks' treatment duration (Studies 1-3) (Lefkowitz et al 1999; Müller-Lissner et al 2001; Novick et al 2002). Similar to overall AEs, the incidence of AEs leading to study discontinuation was comparable for tegaserod and placebo patients, with the exception of diarrhea and headache. Overall, $1.6 \%$ of patients taking tegaserod discontinued from the studies due to diarrhea compared with $0.3 \%$ of patients taking placebo $(\mathrm{p}<0.05)$, and slightly more tegaserod patients also discontinued due to headache $(1.0 \%$ and $0.8 \%$ of patients in the tegaserod and placebo groups, respectively). Tegaserod was also well tolerated in the repeat tegaserod treatment studies (Müller-Lissner et al 2005; Tack et al 2005). The AEs observed during initial and repeat treatment were comparable, while there was a tendency for their frequency to be lower upon repeat treatment (Table 4) (Tack et al 2005).

Two studies were also conducted to assess the long-term safety and tolerability of tegaserod, given that patients may require treatment for prolonged periods. Both were openlabel, multicenter studies, recruiting patients from primary care or out-patient centers and comprised either 12 months of continuous tegaserod treatment (Tougas et al 2002) or 12 weeks of treatment with an optional 9-month extension (Layer et al 2005). In the first study, 567 patients received tegaserod and approximately half (52.5\%) completed 12 months of treatment. The most common AEs reported reflect those observed in the short-term IBS trials (mild and transient diarrhea [10.1\%], headache [8.3\%], and abdominal pain [7.4\%]). Only one SAE (abdominal pain) was reported as possibly related to tegaserod, and diarrhea was the most common reason for discontinuation $(3.5 \%)$ ) (Tougas et al 2002). Safety data from the second study were similar, also reflecting findings in the placebo-controlled trials. Overall, $78.3 \%$ of patients completed the initial 12 weeks of tegaserod and $70.8 \%$ completed the 9 -month extension period. Headache and diarrhea were the most commonly reported AEs in the 12 -week phase $(13.2 \%$ and $9.4 \%$, respectively), while diarrhea was the third most frequent 
$\mathrm{AE}$ in the 9-month extension phase, being reported by $7.5 \%$ of patients.

Overall, these data indicate that tegaserod is well tolerated by patients with IBS-C during short- and longterm treatment as well as repeat treatment. With the exception of diarrhea, which was generally mild and transient and resolved without the need for additional therapy, and possibly headache, the incidence of AEs was similar in tegaserod- and placebo-treated patients.

\section{Special safety considerations: ischemic colitis}

Recently, concerns have been raised regarding the potential risk of ischemic colitis associated with some serotonergic agents. This follows reports that patients taking alosetron and cilansetron have a higher incidence of ischemic colitis than patients taking placebo. These reports showed an incidence of ischemic colitis of 1.1 case per 1000 patientyears and 3.77 cases per 1000 patient-years for alosetronand cilansetron-treated patients, respectively, which is much higher than that observed in IBS patients in general (43-48 cases per 100000 patient-years) (Brinker et al 2004; Singh et al 2004; Chey et al 2005; Chey and Cash 2005).

In contrast to alosetron and cilansetron, which have a different mechanism of action to tegaserod, no cases of ischemic colitis have been reported in tegaserod-treated patients in the clinical trial program, which includes over 14000 patients, equivalent to 4888 patient-years of exposure (Shetzline et al 2005). In addition, a review of post-marketing data reveals that the incidence of ischemic colitis in patients who have used tegaserod is comparable

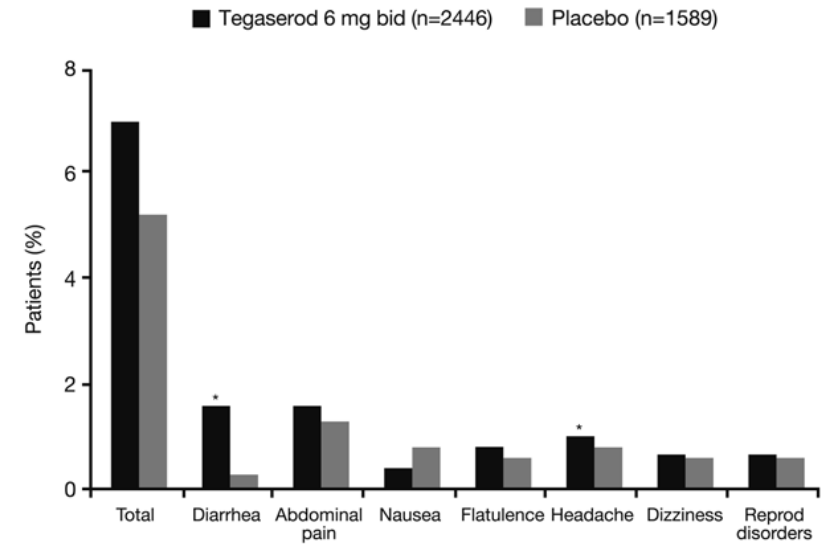

Figure 5 Adverse events $(\geq 0.5 \%)$ leading to discontinuation in pivotal phase III trials of tegaserod. Pooled data from Studies I, 2 and 3 (Müller-Lissner et al 2001; Leftkowitz et al 1999; Novick et al 2002; Novartis, Data on file). Note: ${ }^{*} p<0.05$ vs placebo.

Abbreviations: reprod, reproductive.

with, if not lower (8 cases per 100000 patient-years) than, the incidence observed in the general IBS population (Shetzline et al 2005).

\section{Special safety considerations: cardiac safety}

Cisapride has been associated with fatal ventricular arrhythmias via a mechanism unrelated to its serotonergic action. This resulted in the suspension of its UK license, restricted license in several countries, and its withdrawal from the US market. This consequently has heightened interest in the cardiac safety of other serotonergic agents (Ferriman 2000; Wang et al 2001; Barbey et al 2002). In contrast to cisapride, tegaserod has a favorable cardiac safety

Table 4 Most frequent AEs during repeated tegaserod treatment (ZENSAA [Tack et al 2005]), regardless of study drug relationship

\begin{tabular}{|c|c|c|c|c|}
\hline & \multicolumn{2}{|l|}{ First treatment } & \multicolumn{2}{|c|}{ Repeated treatment ${ }^{a}$} \\
\hline & $\begin{array}{l}\text { Tegaserod }(n=2 \mid 32) \\
n(\%)\end{array}$ & $\begin{array}{l}\text { Placebo }(n=525) \\
n(\%)\end{array}$ & $\begin{array}{l}\text { Tegaserod }(n=487) \\
n(\%)\end{array}$ & $\begin{array}{l}\text { Placebo }(n=494) \\
n(\%)\end{array}$ \\
\hline Headache & II 8 (5.5) & $26(5.0)$ & $20(4.1)$ & $18(3.6)$ \\
\hline Diarrhea & $81(3.8)^{b}$ & $3(0.6)$ & $9(1.8)^{c}$ & $2(0.4)$ \\
\hline Abdominal pain & $48(2.3)$ & $13(2.5)$ & $5(1.0)$ & $6(1.2)$ \\
\hline Nausea & $47(2.2)$ & $6(1.1)$ & $2(0.4)$ & $2(0.4)$ \\
\hline Nasopharyngitis & $46(2.2)$ & $8(1.5)$ & $6(1.2)$ & $5(1.0)$ \\
\hline Influenza & $24(I . I)$ & $7(1.3)$ & $\mathrm{I}(0.2)$ & $2(0.4)$ \\
\hline Abdominal pain (upper) & $23(1.1)$ & $3(0.6)$ & $3(0.6)$ & $2(0.4)$ \\
\hline Back pain & $20(0.9)$ & $8(1.5)$ & $5(1.0)$ & $5(1.0)$ \\
\hline Dyspepsia & II (0.5) & $5(1.0)$ & $2(0.4)$ & $2(0.4)$ \\
\hline Urinary tract infection & II (0.5) & $6(1.1)$ & $5(1.0)$ & $3(0.6)$ \\
\hline Dysmenorrhea & II (0.5) & $3(0.6)$ & $2(0.4)$ & $5(1.0)$ \\
\hline
\end{tabular}

Note: a Regardless of relationship to study drug; Includes only first treatment tegaserod patients who received repeated treatment; ${ }^{b} \mathrm{P}<0.000 \mathrm{I} ;{ }^{\mathrm{d}} \mathrm{p}=0.04$, tegaserod vs placebo. Copyright (C) 2005. Reproduced with permission from BMJ from Tack J, Müller-Lissner S, Bytzer P, et al. 2005. A randomised controlled trial assessing the efficacy and safety of repeated tegaserod therapy in women with irritable bowel syndrome with constipation (IBS-C). Gut, 54:I707-I3. 
profile and is not associated with any clinically significant cardiac abnormalities. In particular, no alterations of ECG parameters including QT-interval measurements have been observed (Morganroth et al 2002).

\section{Special safety considerations: abdominal and pelvic surgery}

Patients with IBS have a relatively high incidence of abdominal/pelvic surgeries. For example, they are twice as likely to undergo a cholescystectomy and four times more likely to undergo appendectomy than healthy people (Hasler and Schoenfeld 2003). In the US, prescribing information for tegaserod notes that trials in IBS-C patients demonstrated an increase in abdominal surgeries in tegaserod $(0.3 \%)$ compared with placebo $(0.2 \%)$ patients, primarily due to more cholecystectomies $(0.17 \%$ and $0.06 \%$, respectively). The FDA specified that tegaserod is contraindicated in patients with gallbladder disease, suspected sphincter of oddi dysfunction, or abdominal adhesions. However, a recent expert analysis of almost 10000 patients in tegaserod clinical trials found the incidence of abdominal/pelvic surgery cases, including cholescystectomy, was comparable in tegaserodand placebo-treated patients (Schoenfeld 2004), and there is no evidence that tegaserod has an effect on gallbladder or sphincter of oddi function in healthy women or those with IBS-C (Fisher et al 2003, 2004).

\section{Special safety considerations: pregnancy and breast feeding}

Pregnancy was investigated in preclinical studies of tegaserod in rats and rabbits at 90 and 360 times the human dose of $6 \mathrm{mg}$ bid, respectively. No harmful effects of tegaserod were reported on pregnancy, embryonic or fetal development, parturition or postnatal development (AppelDingemanse 2002). Pregnancy was an exclusion factor in the tegaserod clinical trial program, and all participating women of child-bearing age were required to use a medically approved method of contraception. Despite this, there were $35(0.43 \%)$ pregnancies in tegaserod and $18(0.40 \%)$ pregnancies in placebo groups. Although these patients withdrew from the studies as protocol violators, there was no indication that tegaserod had a detrimental effect on pregnancy or fetal development (Novartis. Data on file). However, as no controlled studies of tegaserod have been performed in pregnant women, its use during pregnancy is not recommended.
Studies in lactating rats revealed that following oral administration of tegaserod, levels of the drug were approximately three-fold higher in milk than in plasma. This suggests that a suckling infant will ingest tegaserod via breast milk. Consequently, it is recommended that tegaserod is not prescribed to women who are breast-feeding.

\section{Drug-drug interactions and special patient populations}

The liver and kidneys play an important role in eliminating tegaserod from the body. Tegaserod can be metabolized by hepatic cytochrome P450 isozymes (CYP P450) or excreted in urine and feces (Appel-Dingemanse 2002). Other drugs are also metabolized by CYP P450, but there is no evidence of drug-drug interactions between tegaserod and such drugs, including theophylline (Zhou, Khalilieh, et al 2001), dextromethorphan (Kalbag et al 2000), digoxin (Zhou, Horowitz, et al 2001), warfarin (Ledford et al 2000), oral contraceptives (Zhou et al 2000), or antidepressants (Vickers et al 2001; Appel-Dingemanse 2002). These findings indicate that tegaserod can be safely administered alongside these commonly used drugs, with no need for dosage adjustments.

Due to the involvement of the liver and kidneys in the metabolism and excretion of tegaserod, the effects of tegaserod in patients with hepatic and renal disease were studied. Results showed that plasma concentrations of tegaserod in patients with mild-to-moderate liver disease, mild-to-moderate renal impairment, and in patients requiring renal dialysis were comparable with levels in healthy controls. Therefore, dose-adjustment of tegaserod is not required in these patients (Zhou et al 1999; AppelDingemanse 2002).

\section{Concluding remarks}

The efficacy and safety of tegaserod as a treatment for IBS$\mathrm{C}$ have been extensively investigated. Data from randomized, placebo-controlled trials conducted in numerous countries suggest that compared with placebo, tegaserod provides rapid, sustained, and statistically significant relief of overall IBS symptoms as well as individual symptoms of abdominal pain/discomfort, bloating, and constipation. These effects are also observed during repeat treatment, which is important given the chronic and recurring nature of IBS symptoms. The improvements in IBS symptoms observed with tegaserod in comparison with placebo are within the range observed with other 
serotonergic agents. Moreover, efficacy has been confirmed in open-label trials performed in real-life clinical settings, thereby reflecting the response to treatment physicians may observe in their patients. Tegaserod is associated with significant improvements in patients' QoL and work productivity and is well tolerated, including over long-term and repeated treatments. Diarrhea, the only AE consistently associated with tegaserod therapy, is generally mild, of short duration, and resolved without therapy. Overall, tegaserod provides significant improvements for patients with IBS$\mathrm{C}$, without compromising safety. Thus, it can be regarded as an appropriate treatment option from the current agents available for IBS-C.

\section{Acknowledgments}

The authors would like to acknowledge the editorial support and contribution of Dr Siân Beavan of ACUMED ${ }^{\circledR}$ to this manuscript. ACUMED's contribution was funded by Novartis Pharma AG

\section{References}

Appel-Dingemanse S. 2002. Clinical pharmacokinetics of tegaserod, a serotonin 5-HT(4) receptor partial agonist with promotile activity. Clinical Pharmacokinetics, 41:1021-42.

Barbey JT, Lazzara R Zipes DP. 2002. Spontaneous adverse event reports of serious ventricular arrhythmias, QT prolongation, syncope, and sudden death in patients treated with cisapride. $J$ Cardiovasc Pharmacol Ther, 7:65-76.

Bardhan KD, Forbes A, Marsden C, et al. 2004. The effects of withdrawing tegaserod treatment in comparison with continuous treatment in irritable bowel syndrome patients with abdominal pain/discomfort, bloating and constipation: a clinical study. Aliment Pharmacol Ther, 20:213-22.

Bijkerk CJ, de Wit NJ, Stalman WA, et al. 2003. Irritable bowel syndrome in primary care: the patients' and doctors' views on symptoms, etiology and management. Can J Gastroenterol, 17:363-8.

Brandt LJ, Bjorkman D, Fennerty B, et al. 2002. Systematic review on the management of irritable bowel syndrome in North America. Am J Gastroenterol, 97(Suppl):S7-26.

Brinker AD, Mackey AC, Prizont R. 2004. Tegaserod and ischemic colitis. N Engl J Med, 351:1361-4; discussion 1361-4.

Camilleri M. 2005. Mechanisms in IBS: something old, something new, something borrowed. Neurogastroenterol Motil, 17:1-6.

Chey W, Chang L, Harris L, et al. 2005. Incidence of ischemic colitis in clinical trials and post-marketing surveillance amongst patients using alosetron after blinded adjudication. Gastroenterol Clin Biol, 128:T1139.

Chey WD, Cash BD. 2005. Cilansetron: a new serotonergic agent for the irritable bowel syndrome with diarrhoea. Expert Opin Investig Drugs, 14:185-93.

Coates MD, Mahoney CR, Linden DR, et al. 2004. Molecular defects in mucosal serotonin content and decreased serotonin reuptake transporter in ulcerative colitis and irritable bowel syndrome. Gastroenterology, 126:1657-64.

Coffin B, Farmachidi JP, Rueegg P, et al. 2003. Tegaserod, a 5-HT receptor partial agonist, decreases sensitivity to rectal distension in healthy subjects. Aliment Pharmacol Ther, 17:577-85.
[CPMP] European Committee for Medicinal Products for Human Use 2003. Points to consider on the evaluation of medicinal products for the treatment of irritable bowel syndrome [online]. Accessed on . URL: http://www.emea.eu.int/pdfs/human/ewp/078597en.pdf.

Crowell MD. 2004. Role of serotonin in the pathophysiology of the irritable bowel syndrome. Br J Pharmacol, 141:1285-93.

Degen L, Matzinger D, Merz M, et al. 2001. Tegaserod, a 5-HT4 receptor partial agonist, accelerates gastric emptying and gastrointestinal transit in healthy male subjects. Aliment Pharmacol Ther, 15:1745-51.

Dunger-Baldauf C, Nyhlin H, Rueegg P, et al. 2003. Subject's global assessment of satisfactory relief as a measure to assess treatment effect in clinical trials in irritable bowel syndrome. Am J Gastroenterol, 98:S269.

Earnest D, Ruegg P, Dunger-Baldauf C, et al. 2002. Diarrhea in patients treated with tegaserod for irritable bowel syndrome with constipation (IBS-C) is infrequent and usually self-limited. Am J Gastroenterol, 97(Suppl):S277.

Ferriman A. 2000. UK licence for cisapride suspended. BMJ, 321:259.

Fioramonti J, Million M, Bueno L. 1998. Investigations on a 5-HT agonist (SDZ HTF 919) and its main metabolite in conscious dogs: effects on gastrointestinal motility and impaired gastric emptying. Gastroenterology, 114:A752.

Fisher R, Thistle J, Lembo A, et al. 2003. What is the impact of tegaserod on gallbladder emptying? Am J Gastroenterol, 98:S270-1.

Fisher R, Thistle J, Lembo A, et al. 2004.Tegaserod does not alter fasting or meal-induced biliary tract motility. Am J Gastroenterol, 99:13429.

Frank L, Kleinman L, Rentz A, et al. 2002. Health-related quality of life associated with irritable bowel syndrome: comparison with other chronic diseases. Clin Ther, 24:675-89.

Gershon MD. 1999. Review article: roles played by 5-hydroxytryptamine in the physiology of the bowel. Aliment Pharmacol Ther, 13(Suppl 2):15-30.

Gershon MD. 2004. Review article: serotonin receptors and transporters - roles in normal and abnormal gastrointestinal motility. Aliment Pharmacol Ther, 20(Suppl 7):3-14.

Gralnek IM, Hays RD, Kilbourne A, et al. 2000. The impact of irritable bowel syndrome on health-related quality of life. Gastroenterology, 119:654-60.

Grider JR, Foxx-Orenstein AE, Jin J-G. 1998. 5-Hydroxytryptamine receptor agonists initiate the peristaltic reflex in human, rat and guineapig intestine. Gastroenterology, 115:370-80.

Hahn B, Yan S, Strassels S. 1999. Impact of irritable bowel syndrome on quality of life and resource use in the United States and United Kingdom. Digestion, 60:77-81.

Hasler WL, Schoenfeld P. 2003. Abdominal and pelvic surgery in patients with irritable bowel syndrome. Aliment Pharmacol Ther, 17:997-1005.

Hasler WL, Schoenfeld P. 2004. Safety profile of tegaserod, a 5-HT4 receptor agonist, for the treatment of irritable bowel syndrome. Drug Safety, 27:619-31.

Hungin AP, Whorwell PJ, Tack J, et al. 2003. The prevalence, patterns and impact of irritable bowel syndrome: an international survey of 40 000 subjects. Aliment Pharmacol Ther, 17:643-50.

Hungin AP, Chang L, Dennis EH, et al. 2005. Irritable bowel syndrome in the United States: symptom patterns and impact. Aliment Pharmacol Ther, 21:1365-75.

Jin JG, Foxx-Orenstein E, Grider JR. 1999. Propulsion in guinea pig colon induced by 5 -hydroxytryptamine (HT) via $5-\mathrm{HT}_{4}$ and $5-\mathrm{HT}_{3}$ receptors. Pharmacol Experimental Ther, 288:93-7.

Kalbag J, Migoya E, Osborne S, et al. 2000. Tegaserod does not significantly affect the pharmacokinetics of dextromethorphan in healthy subjects. Gastroenterology, 118(Suppl 2 Pt 2):A71179.

Kellow J, Lee OY, Chang FY, et al. 2003. An Asia-Pacific, double blind, placebo controlled, randomised study to evaluate the efficacy, safety, and tolerability of tegaserod in patients with irritable bowel syndrome. Gut, 52:671-6. 
Kozma CM, Barghout V, Slaton T, et al. 2002. A comparison of officebased physician visits for irritable bowel syndrome and for migraine and asthma. Manag Care Interface, 15:40-3, 49.

Layer P, Keller J, Müller-Lissner S, et al. 2005. Tegaserod: Long-term treatment for irritable bowel syndrome patients with constipation in primary care. Digestion, 71:238-44.

Ledford P, On N, Ligueros-Saylan M, et al. 2000. Tegaserod does not significantly affect the pharmacokinetics and pharmacodynamics of warfarin in healthy subjects. Gastroenterology, 118(Suppl 2):A1184 (Abstract 5445).

Lefkowitz M, Shi Y, Schmitt C, et al. 1999. The 5-HT partial agonist, tegaserod, improves abdominal discomfort/pain and normalizes altered bowel function in irritable bowel syndrome (IBS). Am J Gastroenterol, 94:266.

Lesbros-Pantoflickova D, Michetti P, Fried M, et al. 2004. Meta-analysis: the treatment of irritable bowel syndrome. Aliment Pharmacol Ther, 20:1253-69.

Malagelada JR. 2006. IBS: making a positive diagnosis. Int J Clin Pract, 60:57-63.

Morganroth J, Ruegg PC, Dunger-Baldauf C, et al. 2002. Tegaserod, a 5hydroxytryptamine type 4 receptor partial agonist, is devoid of electrocardiographic effects. Am J Gastroenterol, 97:2321-7.

Müller-Lissner SA, Fumagalli I, Bardhan KD, et al. 2001. Tegaserod, a 5$\mathrm{HT}_{4}$ receptor partial agonist, relieves symptoms in irritable bowel syndrome patients with abdominal pain, bloating and constipation. Aliment Pharmacol Ther, 15:1655-66.

Müller-Lissner S, Pirk O. 2002. Irritable bowel syndrome in Germany. A cost of illness study. Eur J Gastroenterol Hepatol, 14:1325-9.

Müller-Lissner S, Holtmann G, Rueegg P, et al. 2005. Tegaserod is effective in the initial and retreatment of irritable bowel syndrome with constipation. Aliment Pharmacol Ther, 21:11-20.

Novartis. Data on file.

Novick J, Miner P, Krause R, et al. 2002. A randomized, double-blind, placebo-controlled trial of tegaserod in female patients suffering from irritable bowel syndrome with constipation. Aliment Pharmacol Ther, $16: 1877-88$

Nyhlin H, Bang C, Elsborg L, et al. 2004. A double-blind, placebocontrolled, randomized study to evaluate the efficacy, safety and tolerability of tegaserod in patients with irritable bowel syndrome. Scand J Gastroenterol, 39:119-26.

Patel SM, Stason WB, Legedza A. 2005. The placebo effect in irritable bowel syndrome trials: a meta-analysis. Neurogastroenterol Motil, 17:332-40.

Patrick DL, Barghout V, Pecher E, et al. 2005. Tegaserod significantly improves health-related quality of life and patient satisfaction in patients with irritable bowel syndrome with constipation. Gastroenterology, 128:M994.

Pfannkuche HJ, Buhl T, Gamse R, et al. 1995. The properties of a new prokinetically active drug SDZ HTF 919. Neurogastroenterol Motil, 7:280.

Prather CM, Camilleri M, Zinsmeister AR, et al. 2000. Tegaserod accelerates orocecal transit in patients with constipation-predominant irritable bowel syndrome. Gastroenterology, 118:463-8.

Quartero A, Meineche-Schmidt V, Muris J, et al. 2005. Bulking agents, antispasmodic and antidepressant medication for the treatment of irritable bowel syndrome. Cochrane Database Syst Rev, 2:CD003460.

Reilly MC, Barghout V, McBurney CR, et al. 2005. Effect of tegaserod on work and daily activity in irritable bowel syndrome with constipation. Aliment Pharmacol Ther, 22:373-80.
Sabate J, Bouhassira D, Poupardin C, et al. 2005. Antinociceptive effect of tegaserod in female IBS constipated patients. Gastroenterology, 128(Suppl 2):A-468

Schikowski A, Mathis C, Thewissen M, et al. 1999. Dose-dependent modulation of rectal afferent sensitivity by a 5-HT4 receptor agonist. Gastroenterology, 116:A643.

Schmulson M, Lee OY, Chang L, et al. 1999. Symptom differences in moderate to severe IBS patients based on predominant bowel habit. Am J Gastroenterol, 94:2929-35.

Schoenfeld P. 2004. Systematic review: incidence of abdominal/pelvic surgery amongst patients using tegaserod in randomized controlled trials. Aliment Pharmacol Ther, 19:263-9.

Schoenfeld P. 2005. Efficacy of current drug therapies in irritable bowel syndrome: what works and does not work. Gastroenterol Clin North Am, 34:319-35.

Shetzline MA, Cohard-Radice M, Joelsson B. 2005. Ischemic colitis, irritable bowel syndrome, and tegaserod - an alternative viewpoint. Pharmacotherapy, 25:1684-5.

Singh G, Mithal A, Kahler K, et al. 2004. Patients with irritable bowel syndrome have a high risk of developing colon ischemia. Gut, 53(Suppl VI):A66.

Stoner MC, Arcuni JC, John JL, et al. 1999. A selective 5-HT receptor agonist induces cAMP-mediated $\mathrm{Cl}$ efflux from rat colonocytes. Gastroenterology, 116:G287.

Tack J, Müller-Lissner S, Bytzer P, et al. 2005. A randomised controlled trial assessing the efficacy and safety of repeated tegaserod therapy in women with irritable bowel syndrome with constipation (IBS-C). Gut, 54:1707-13.

Thompson WG, Longstreth GF, Drossman DA, et al. 1999. Functional bowel disorders and functional abdominal pain. Gut, 45(Suppl 2):1143-7.

Tougas G, Snape WJ, Otten MH, et al. 2002. Long-term safety of tegaserod in patients with constipation-predominant irritable bowel syndrome. Aliment Pharmacol Ther, 16:1701-8.

Uscanga-Dominguez L, Cohen Munoz V. 2003. Relapse of symptoms following withdrawal of tegaserod treatment in irritable bowel syndrome with constipation (IBS-C). Gastroenterology, 124(Suppl 1):A-571.

Valenzuela J, Alvarado J, Cohen H, et al. 2004. Latin-American consensus document on irritable bowel syndrome. Gastroenterol Hepatol, 27:325-43.

Vickers AEM, Zollinger M, Dannecker R, et al. 2001. In vitro metabolism of tegaserod in human liver and intestine: assessment of drug interactions. Drug Metab Dispos, 29:1269-76.

Wang SH, Lin CY, Huang TY, et al. 2001. QT interval effects of cisapride in the clinical setting. Int $J$ Cardiol, 80:179-83.

Zhou H, McLeod J, Alladina L. 1999. Pharmacokinetics of HTF 919 not altered in subjects with severe renal insufficiency requiring hemodialysis. Clin Pharmacol Ther, 65:P108-11.

Zhou H, Walter Y, Hubert M, et al. 2000. Tegaserod (HTF 919) does not decrease the effectiveness of an oral contraceptive when coadministered to healthy female subjects. Gastroenterology, 118(Suppl 2 Pt 2):A5539.

Zhou H, Horowitz A, Ledford PC, et al. 2001. The effects of tegaserod (HTF 919) on the pharmacokinetics and pharmacodynamics of digoxin in healthy subjects. J Clin Pharmacol, 41:1131-9.

Zhou H, Khalilieh S, Svendsen K, et al. 2001. Tegaserod coadministration does not alter the pharmacokinetics of theophylline in healthy subjects. J Clin Pharmacol, 41:987-93. 